(2) Open Access Full Text Article

\title{
Successful treatment of prostaglandin-induced cystoid macular edema with subtenon triamcinolone
}

This article was published in the following Dove Press journal:

Clinical Ophthalmology

17 December 2012

Number of times this article has been viewed

\section{Kazuki Matsuura' \\ Shinichi Sasaki ${ }^{2}$ \\ Ryu Uotani ${ }^{3}$}

'Nojima Hospital, Kurayoshi, ${ }^{2}$ Kushimoto Rehabilitation Center, Kushimoto, ${ }^{3}$ Tottori University, Yonago, Japan
Correspondence: Kazuki Matsuura Nojima Hospital, 27I4-I Sesaki-machi, Kurayoshi City, Tottori 682-0863, Japan

Email i-mnys200I@za.ztv.ne.jp or matsu224@ncn-k.net
Purpose: Cystoid macular edema (CME) is associated with the use of prostaglandin eye drops after cataract surgery. The study aim was to report on the treatment of two CME patients with subtenon triamcinolone injections.

Methods: Case one was a 70-year-old woman who underwent uneventful cataract surgery. Travoprost was administrated at 10 weeks after surgery, and CME occurred at 13 weeks after surgery. Case two was an 85-year-old man who underwent intraocular lens extraction and an intraocular lens suture operation. Latanoprost was readministered after the surgery. The patient complained of blurred vision 3 years later.

Results: For both cases, discontinuation of the prostaglandin eye drops, subsequent initiation of treatment with diclofenac eye drops, and subtenon injection of triamcinolone was followed by the rapid disappearance of the CME. After the CME had disappeared for 3 months, the prostaglandin eye drops were resumed. Diclofenac was added in case two. No CME recurrence was seen in either case over 2 years.

Conclusion: Subtenon triamcinolone injection can be effective for CME associated with prostaglandin eye liquid after cataract surgery. Prostaglandin eye liquid that causes CME is not necessarily precluded for future use if administered under careful observation.

Keywords: cystoid macula edema, subtenon triamcinolone injection, prostaglandin eye drops, cataract surgery

\section{Introduction}

The administration of prostaglandin after cataract surgery can lead to cystoid macular edema (CME). Typically, the treatment comprises the discontinuation of eye drops, ${ }^{1}$ corticosteroid eye drops, and nonsteroidal antiinflammatory drugs (NSAIDs), such as diclofenac. The administration of dorzolamide hydrochloride eye drops and oral acetazolamide may also be appropriate..$^{2-10}$ In many cases, however, the recovery can require 1 month or more. . $^{3-6,8-10}$

In this study, two cases in which subtenon triamcinolone injection resulted in the early disappearance of CME associated with prostaglandin treatment after cataract surgery are presented. In both cases, the readministration of prostaglandin did not cause a recurrence of the CME at 2 years or more after surgery.

\section{Case one: a 70-year-old woman}

Although the optic disc did not reveal any glaucomatous change, the intraocular pressure (IOP) often exceeded the mid-twenties (average: $23 \mathrm{mmHg}$ ). The patient was administered tafluprost before the surgery. Eight weeks after an acrylic intraocular 
lens implantation by corneoscleral incision, the tafluprost treatment was resumed. Ten weeks after the surgery, the tafluprost treatment was discontinued, and travoprost treatment was initiated. The IOP was controlled at $16-19 \mathrm{mmHg}$. Thirteen weeks after the surgery, the patient complained of a reduction in visual acuity (20/40). CME was identified in the right eye by optical coherence tomography (OCT) findings (Figure 1A), and was treated with an injection of subtenon triamcinolone. Discontinuance of travoprost and the initiation of diclofenac eye drops improved the visual acuity (20/20) and resulted in a rapid improvement in the OCT findings within a few days (Figure 1B). After 3 months, travoprost was resumed and diclofenac was discontinued 6 months after surgery. No recurrence has occurred for a period of 2 years (Figure 1C), and the IOP has been controlled at 16-19 mmHg.

\section{Case two: an 85-year-old man}

In 2004, the patient underwent intraocular lens suture surgery, including anterior vitreous cutting, for intraocular lens dislocation in his left eye. The patient had been treated with latanoprost prior to the surgery, and treatment with latanoprost was continued after it. The IOP was controlled at $11-13 \mathrm{mmHg}$. Visual acuity in his left eye remained at 20/40 to $30 / 40$. However, the patient complained of blurred vision early in
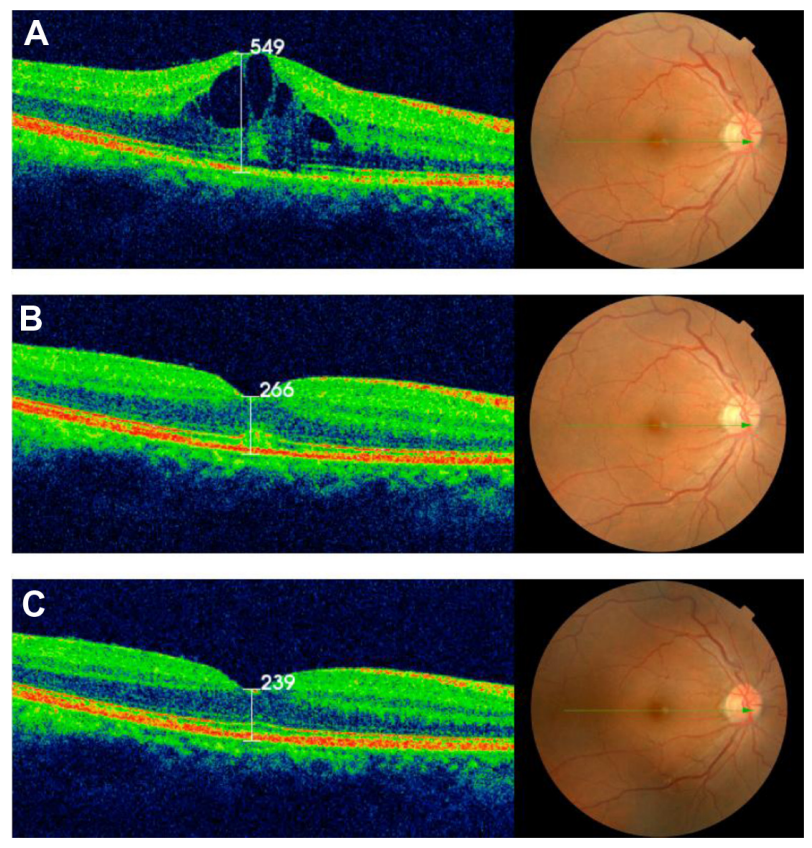

Figure I (A) Vertical section of the macular area of the right eye by optical coherence tomography showing cystoid macular edema. (B) Vertical section of the macular area of the right eye 2 days after subtenon triamcinolone injection. A quick recovery was observed. (C) Two years after subtenon triamcinolone injection, no recurrence of cystoid macular edema was observed.
July 2007. On August 1, his visual acuity was 20/200, and the OCT findings indicated CME (Figure 2A). Latanoprost was subsequently discontinued. On August 4, the patient was given a subtenon triamcinolone injection. By August 7, his visual acuity had recovered to 20/40, and the OCT findings showed improvement (Figure 2B). After 3 months, latanoprost was resumed treated with diclofenac. No recurrence of the CME has occurred for a period of 3 years, and IOP has been controlled at 10-15 $\mathrm{mmHg}$ (Figure 2C).

\section{Discussion}

Risk factors for CME due to prostaglandin eye drops include a surgical history of glaucoma operations, aphakia, complicated cataract surgery, scleral buckling, and vitrectomy, as well as a history of uveitis and other retinal diseases.
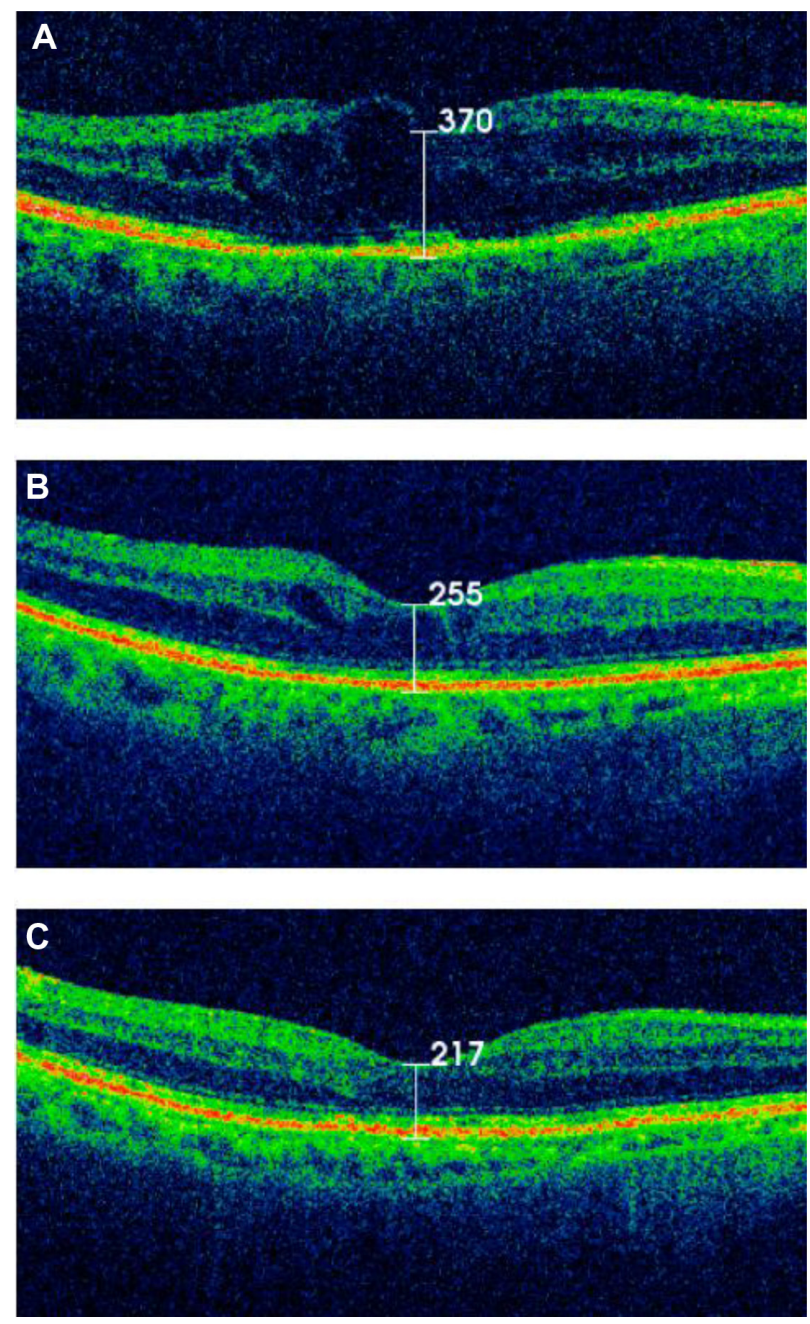

Figure 2 (A) Vertical section of the macular area of the left eye by optical coherence tomography showing cystoid macular edema. (B) Vertical section of the macular area of the left eye 2 days after subtenon triamcinolone injection. A quick recovery with a mild case of cystoid macular edema was observed. (C) Three years after subtenon triamcinolone injection, no recurrence of cystoid macular edema was observed. 
Patients without risk factors for developing the condition are rare. ${ }^{1-7}$ In terms of the prevalence of CME, Wand et al reported that two of 38 high-risk cases (5.3\%) developed clinical CME. ${ }^{4}$ Meanwhile, Furuichi et al found that none of the 68 cases without any of the reported risk factors developed clinical CME. ${ }^{11}$ In cases without known risk factors, CME can appear within 2-3 months of surgery. ${ }^{10,12}$ Meanwhile, in high-risk cases, CME can even appear several years after the surgery. ${ }^{1,3-5,7,13}$ In cases without the known risk factors for CME, the condition may develop because of temporary damage to the blood-aqueous barrier immediately after surgery. In cases involving known risk factors, the damage to the blood-aqueous barrier is protracted, resulting in the continuance of conditions that lead to CME in the long term. ${ }^{14}$

Case one presented CME while undergoing benzalkonium chloride-free travoprost treatment. Miyake et al reported that preservatives in the prostaglandin eye drops have a greater influence on the development of CME when compared to the base compound. ${ }^{15}$ Additionally, Watanabe et al reported CME cases that developed when latanoprost treatment was initiated after 3 years of treatment with preservative-containing unoprostone. ${ }^{7} \mathrm{CME}$ has similarly been reported when latanoprost was added to a drug regimen that already included several types of eye drops containing preservatives. ${ }^{2-4}$ While preservatives may promote latanoprost-induced CME, the preservatives alone do not provide a sufficient explanation for the development of this condition. Esquenazi studied a case of CME induced by benzalkonium chloride-free travoprost. ${ }^{9}$ In case one of this study, benzalkonium chloride-free travoprost appears to be the cause of the CME. No other eye drops were used during the treatment, and the patient had no underlying diseases (eg, diabetes) that could have caused CME.

Because the risk of CME is high immediately after cataract surgery, NSAIDs should be used along with a prostaglandin eye liquid. ${ }^{16}$ In case one, the administration of diclofenac was discontinued 6 months after surgery since it was determined that the danger of developing CME had decreased, although the treatment with travoprost was continued. No recurrence has been observed for a period of 2 years. In case two, treatment with the diclofenac eye drops and latanoprost was continued because it was believed that the damage to the blood-aqueous barrier would be protracted. No indications of CME were observed 3 years after surgery. Wand and Gaudio reported two cases in which CME treated with NSAIDs did not recur after unoprostone and bimatoprost treatment was resumed. ${ }^{13}$ Further, this group reported one case in which CME did not recur after latanoprost treatment was resumed. ${ }^{4}$ Meanwhile, Callanan et al reported one case in which CME not treated with NSAIDs recurred after resumption of latanoprost treatment. ${ }^{3}$ Prostaglandin has no systemic side effects and is currently the most effective drug as an eye liquid. When possible, the use of this drug should be resumed after a certain period of time. In certain cases, the concomitant use of NSAIDs and prostaglandin eye drops can be greatly beneficial to patients.

Subtenon injection of triamcinolone is considered the standard treatment for CME caused by diabetic retinopathy, retinal vein occlusion, uveitis, or other conditions. However, no studies have been conducted on the effectiveness of this treatment for CME caused by the use of prostaglandin eye drops. Several treatment options are available for prostaglandin-induced CME, including NSAIDs, steroids, dorzolamide hydrochloride eye drops, and oral acetazolamide; however, in many cases, recovery can take as long as 1 month or more. ${ }^{3-6,8-10}$ Triamcinolone treatment poses the risk of the typical side effects caused by steroids, but the risk of infection should not be a concern if its usage is avoided immediately after the surgery. Case one had no surgical complications and presented CME during the use of travoprost; therefore, aggressive care was chosen. Case two presented blindness in the right eye, and there was a strong desire for a quick recovery of the left eye. The authors believe that in such a case, subtenon triamcinolone injection is the selectable course of treatment.

\section{Conclusion}

Subtenon triamcinolone injection can be effective for CME after cataract surgery. Moreover, the current findings suggest that the prostaglandin eye drops that potentially led to the CME can be resumed under careful observation.

\section{Acknowledgments}

The authors would like to thank Mr Mitsuharu Ikeda for assistance with the manuscript.

\section{Disclosure}

The authors report no conflicts of interest in this work.

\section{References}

1. Ayyala RS, Cruz DA, Margo CE, et al. Cystoid macular edema associated with latanoprost in aphakic and pseudophakic eyes. Am J Ophthalmol. 1998;126(4):602-604.

2. Moroi SE, Gottfredsdottir MS, Schteingart MT, et al. Cystoid macular edema associated with latanprost therapy in a case of patients with glaucoma and ocular hypertension. Ophthalmology. 1999;106(5): 1024-1029.

3. Callanan D, Fellman RL, Savage JA. Latanoprost-associated cystoid macular edema. Am J Ophthalmol. 1998;126(1):134-135. 
4. Wand M, Gaudio AR, Shields MB. Latanoprost and cystoid macular edema in high-risk aphakic or pseudophakic eyes. J Cataract Refract Surg. 2001;27(9):1397-1401.

5. Tokunaga T, Kashiwagi K, Saito J, et al. A case of cystoid macular edema associated with latanoprost ophthalmic solution. Jpn $J$ Ophthalmol. 2002;46(6):656-659.

6. Jager M, Jonas JB. Cytoid macular edema associated with latanoprost therapy in a pseudophakic vitrectomized patient after removal of silicone oil endotamponade. Eur J Ophthalmol. 2003;13(2):221-222.

7. Watanabe K, Hayasaka S, Hayasaka Y, Nagaki Y, Watanabe K. Cystoid macular edema associated with latanoprost use in a pseudophakic eye with a history of surgical complications. Jpn J Ophthalmol. 2003;47(1): 110-112.

8. Carrillo MM, Nicolela MT. Cystoid macular edema in a low-risk patient after switching from latanoprost to bimatoprost. Am J Ophthalmol. 2004;137(5):966-968.

9. Esquenazi S. Cystoid macular edema in a pseudophakic patient after switching from latanoprost to BAK-free travoprost. J Ocul Pharmacol Ther. 2007;23(6):567-570.

10. Altintas O, Yuksel N, Karabas VL, Dermirci G. Cystoid macular edema associated with latanoprost after uncomplicated cataract surgery. Eur J Ophthalmol. 2005;15(1):158-161.
11. Furuichi M, Chiba T, Abe K, et al. Cystoid macular edema associated with topical latanoprost in glaucomatous eyes with a normally functioning blood-ocular barrier. J Glaucoma. 2001;10(3):233-236.

12. Yeh PC, Ramanathan S. Latanoprost and clinically significant cystoid macular edema after uneventful phacoemulsification with intraocular lens implantation. J Cataract Refract Surg. 2002;28(10):1814-1818.

13. Wand M, Gaudio AR. Cystoid macular edema associated with ocular hypotensive lipids. Am J Ophthalmol. 2002;133(3):403-405.

14. Ohrloff C, Schalnus R, Rothe R, Spitznas M. Role of the posterior capsule in the aqueous-vitreous barrier in aphakic and pseudophakic eyes. J Cataract Refract Surg. 1990;16(2):198-201.

15. Miyake K, Ota I, Ibaraki N, et al. Enhanced disruption of the bloodaqueous barrier and the incidence of angiographic cystoid macular edema by topical timolol and its preservative in early postoperative pseudophakia. Arch Ophthalmol. 2001;119(3):387-394.

16. Miyake K, Ota I, Maekubo K, Ichihashi S, Miyake S. Latanoprost accelerates disruption of the blood-aqueous barrier and the incidence of angiographic cystoid macular edema in early postoperative pseudophakias. Arch Ophthalmol. 1999;117(1):34-40.
Clinical Ophthalmology

\section{Publish your work in this journal}

Clinical Ophthalmology is an international, peer-reviewed journal covering all subspecialties within ophthalmology. Key topics include: Optometry; Visual science; Pharmacology and drug therapy in eye diseases; Basic Sciences; Primary and Secondary eye care; Patient Safety and Quality of Care Improvements. This journal is indexed on

\section{Dovepress}

PubMed Central and CAS, and is the official journal of The Society of Clinical Ophthalmology (SCO). The manuscript management system is completely online and includes a very quick and fair peer-review system, which is all easy to use. Visit http://www.dovepress.com/ testimonials.php to read real quotes from published authors. 